\title{
Colonization of Fiber Cells by Colletotrichum graminicola in Wounded Maize Stalks
}

\author{
C. Venard and L. Vaillancourt
}

Department of Plant Pathology, University of Kentucky, Lexington 40546.

Accepted for publication 20 September 2006.

\begin{abstract}
Venard, C., and Vaillancourt, L. 2007. Colonization of fiber cells by Colletotrichum graminicola in wounded maize stalks. Phytopathology 97:438-447.

Colonization of wounded maize stalks by a wild-type strain of Colletotrichum graminicola was compared with colonization by a C. graminicola mutant that is avirulent on maize leaves, and by a wildtype strain of $C$. sublineolum that is normally a pathogen of sorghum but not maize. Local infection by all strains at the wound site resulted in

with the wild-type $C$. graminicola strain, and proceeded specifically through the fiber cells associated with the vascular bundles and the rind. Hyphae emerged from the fiber cells to produce discontinuous secondary lesions. There was no evidence that $C$. graminicola is a vascular wilt pathogen. Resistance of wounded cv. Jubilee maize stalks to the mutant strain of $C$. graminicola and to $C$. sublineolum was associated with restriction of colonization and spread of the pathogen through the fibers, as well as with the limitation of localized destruction of parenchyma cells at the wound site.
\end{abstract} formation of primary lesions consisting of disintegrated parenchyma cells beneath an intact rind and epidermis. However, subsequent rapid longitudinal expansion of the primary lesion occurred only in infections
Additional keywords: corn stalk rot, fungal pathogenicity, green fluorescent protein, ZsGreen.
Colletotrichum graminicola (Ces.) Wilson, the causal agent of maize anthracnose, can infect any part of its host plant at any time during the growing season $(8,42)$. However, it occurs most frequently and causes the most damage as anthracnose leaf blight on seedlings and older plants, and anthracnose stalk rot on mature plants at or near anthesis $(8,11,24,25,42)$. Prior to the 1970 s, localized epidemics of anthracnose leaf blight and anthracnose stalk rot had been reported from various countries around the world, but neither disease was considered to be a serious threat in the United States (14). This perception changed during the earlyto-mid 1970s, however, when severe outbreaks of anthracnose leaf blight and anthracnose stalk rot occurred throughout the north central and eastern United States $(22,42)$. Removing highly susceptible germ plasm from maize hybrids has prevented further epidemics on the scale of those seen in the 1970s. Nonetheless, anthracnose is still very common in U.S. maize fields $(1,8,10)$. Anthracnose stalk rot in particular causes significant yield losses every year and it ranks among the most important disease challenges for the maize breeding industry $(18,19)$.

C. graminicola is one of the most aggressive of the stalk rot fungi affecting maize $(8,19,28)$. External anthracnose stalk rot symptoms, when they exist, consist of a shiny black discoloration of the rind tissue. When the infected stalks are cut longitudinally, the interior pith appears dark and rotted $(2,5,8,31,44)$. Severely rotted internodes are structurally weakened, and the plant may fall over or "lodge" as a result. Degeneration of the stalk tissues can also cause premature death of the upper parts of the plant, a symptom called top dieback.

Resistance to anthracnose leaf blight and to anthracnose stalk rot appears to be primarily polygenic $(12,13)$, although several

Corresponding author: L. Vaillancourt; E-mail address: vaillan@uky.edu

doi:10.1094/PHYTO-97-4-0438

(C) 2007 The American Phytopathological Society genes with major effects have also been reported $(3,4)$. Genes conferring resistance to anthracnose leaf blight do not necessarily confer resistance to stalk rot, and vice versa (8). This suggests that the mechanism of resistance to anthracnose leaf blight may be different from that of resistance to stalk rot. In genotypes resistant to anthracnose stalk rot, damage is usually limited to one or a few adjacent internodes, which may nonetheless become extensively rotted, especially postanthesis (2).

Few studies exist that illustrate the process of infection and colonization of maize stalks by $C$. graminicola in detail, though leaf infection has been better characterized $(29,35)$. C. graminicola has been described as causing a vascular wilt in stalks because top dieback symptoms are reminiscent of a wilt disease and because the fungus can be recovered by culturing isolated vascular bundles (8). C. graminicola produces two types of asexual spores. Falcate spores are produced on the surfaces of host tissues in acervuli, and play the primary role in dissemination of the pathogen from plant to plant. Oval spores are produced only inside the infected plant tissues (34). The role of the oval spores in the fungal life cycle is unclear, but because they have reportedly been observed inside xylem vessels (8), it has been suggested that lesion expansion in the stalk occurs as a result of systemic movement of these spores through the vascular tissues within and between internodes $(8,34)$. The objective of this work was to address these hypotheses by observing in detail the colonization of maize stalk tissues, and particularly of vascular tissues in the stalk, by $C$. graminicola. We did see rapid longitudinal spread of the fungus, but this did not typically occur via intact xylem or phloem vascular elements as might be expected for a wilt pathogen. Instead, it preceded specifically through the fiber cells, which are closely associated with the vascular bundles and with the rind. Spread was not due primarily to transport of oval spores, but to the production and elongation of hyphae within these fiber cells. Thus, our results provided no substantial support for the idea that $C$. graminicola acts as a vascular wilt fungus in maize stalks, and they also did not demonstrate an obvious role for oval spores in stalk colonization. 


\section{MATERIALS AND METHODS}

Fungal cultures and production of spore suspensions. C. graminicola strain M1.001, also known as CgM2 (17), was obtained from the late R. Hanau of Purdue University. Strain 6-2 is an insertional mutant derived from M1.001. This mutant causes no symptoms on maize leaves and only very limited lesions on wounded maize stalks (40). The mutant was used here so we could compare a compatible with an incompatible interaction on a single susceptible maize genotype. C. sublineolum isolate $\mathrm{CgS} 11$ was obtained from R. Nicholson of Purdue University. It is pathogenic on sorghum stalks and leaves, but nonpathogenic on maize in the field. It was used here as a control for maize stalk quality. If the plants become too environmentally stressed in the greenhouse, significant rotting of stalks inoculated with $C$. sublineolum can result (L. Vaillancourt, unpublished data).

M1.001, 6-2, CgS11, and their respective green fluorescent transformants were grown on oatmeal agar (Difco Laboratories, Detroit) plates for 2 weeks. Falcate spores were collected by adding $10 \mathrm{ml}$ of sterile water and rubbing the surface of the culture gently with a plastic mini-pestle. The conidial suspension was collected and filtered though sterile glass wool, and the conidia were washed three times in sterile water. The concentration of conidia was adjusted to $5 \times 10^{6}$ spores per milliliter after the third wash.

Fungal transformation. Two different methods were used to produce transformants expressing green fluorescent proteins (GFP). The first was a polyethylene glycol-mediated protocol described previously (40). Protoplasts were transformed using 3 to $9 \mu$ g of linearized plasmids: pCT74 contains an SGFP gene under the control of the Pyrenophora tritici-repentis TOX-A promoter, and a hygromycin phosphotransferase gene as a selectable marker (26). M1.001 was transformed with pCT74 linearized with EcoRI. Strain 6-2, which is already resistant to hygromycin (40), was co-transformed with pAN8-1 and pCT74, both linearized with EcoRI, and transformants were selected on phleomycin and then screened for GFP expression. Plasmids pSM615 and pSM611 both contain the ZsGreen gene (9). pSM615 also contains a hygromycin phosphotransferase gene and was used to transform M1.001. pSM611 contains a geneticin resistance gene and was used to transform strain 6-2. Both plasmids were linearized before use with BamHI. pSM615 and pSM611 were provided by J. Sweigard (Dupont Experimental Station, Wilmington, DE).

We also used a protocol developed for Agrobacterium-mediated transformation of falcate spores (16). Two different plasmids were used. The first, pJF1, contains the same SGFP and hygromycin resistance genes and promoter elements as pCT74 (16). The second plasmid, pBin-GFP-hph, also contains GFP and hygromycin resistance genes, under the control of other promoters (33). All transformants were single-spored and stored on silica at $-80^{\circ} \mathrm{C}$.

Plant growth and inoculation. The sweet corn hybrid cv. Jubilee was chosen for this study because it matures quickly and does not exceed a manageable size for the greenhouse. It is also highly susceptible to anthracnose stalk rot and anthracnose leaf blight and has a historical association with the first epidemics of anthracnose in the United States (42). Jubilee sweet corn seed was a generous gift of Syngenta (Research Triangle Park, NC), and was obtained from Rogers Seed Company (Boise, ID). Plants were grown in the greenhouse in $25-\mathrm{cm}$ pots in a mixture of three parts Pro-Mix BX (Premiere Horticulture Ltd., Riviere $\mathrm{du}$ Loup, PQ, Canada) to two parts sterilized topsoil. Three seeds were planted in each pot. After germination, the seedlings were watered daily to saturation with a solution of $4.75 \mathrm{~g}$ of Miracle-Gro 18-18-21 formulation for tomatoes (Stern's Miracle-Gro Products Inc., Port Washington, NY) per liter. Two plants per pot were ultimately retained. Just prior to anthesis, the sheath tissue was stripped from the second internode above the soil line. The plants were placed on their sides, and a small wound was made in the center of the stripped internode with a sterile dissecting needle $\left(2 \mathrm{~mm}\right.$ in depth). A $10-\mu$ drop of a $5 \times 10^{6}$ conidial suspension, or sterile water as a control, was applied to the wound. The wound was covered with a detached microfuge tube cap and sealed with Parafilm to create a moist chamber. The plants were left on the greenhouse bench overnight. The tube caps were then removed, and the plants were placed upright. The inoculated internodes from two plants were harvested each day starting at 6 days postinoculation (dpi). For each experiment, a minimum of 20 plants was inoculated with each fungal strain or with water. Each experiment was repeated at least three times.

Statistical analysis. Nine different strains of $C$. graminicola were used in this study, including the three nonfluorescent strains (M1.001, 6-2, and CgSl1), and two independent SGFP or ZsGreen transformants of each. Lengths of the primary lesions produced by each strain were measured after splitting inoculated stalks longitudinally. Because measuring required the destruction of the stalks, the expansion of individual lesions could not be analyzed over time. Instead, each data point represents one separate stalk, collected between 6 and 15 dpi. Data were analyzed using the General Linear Model (GLM) procedure that is part of the statistical analysis software (SAS) package (SAS version 1997, SAS Institute, Cary, NC). The Tukey means separation method was applied to the data, with a significance level of $P<0.05$. The effects on average lesion length of different strains (also including the water control) and of incubation time were analyzed.

Fluorescent microscopy. Fungal development in stalk tissues was monitored with a Leica TCS NT confocal microscope (Leica Microsystems Inc., Exton, PA). Infected tissue sections were cut by hand with a razor blade and observed without further treatment. Green fluorescent proteins (GFP and ZsGreen) were excited at $488 \mathrm{~nm}$. Plant cell walls and chloroplasts auto-fluoresce at this excitation wavelength, and this property was used to visualize the plant tissues. However, at lower magnifications, the autofluorescence of the plant cell walls was usually not intense enough to be captured in the micrographs. In a few cases, a laser scanning microscope (Zeiss model 410; Carl Zeiss Inc., Thornwood, NY) or an Olympus FV1000 (Olympus America Inc., Melville, NY) was used. Tissue sections from five stalks inoculated with M1.001 were stained with acridine orange according to the protocol of Guenther and Trail (20) to visualize the fungal nuclei. These samples were observed with an epifluorescence microscope (Zeiss AxioSkop Microscope; Carl Zeiss Jena GmbH, Zeiss Gruppe, Jena, Germany).

Resin embedding and sectioning. We used a tissue fixation and embedding procedure originally developed by Spurr (37). Three internodes each, inoculated with M1.001 strains, 6-2 strains, CgSl1 strains, or water, were selected. Between 5 and 10 pieces, 2 to $3 \mathrm{~mm}$ in length, were dissected from the darkly discolored zone surrounding the primary lesion, or from the wound site in the case of the water controls. One unwounded and uninoculated internode was used as a control: in this case, tissue pieces were dissected from the middle of the internode. Tissue fragments were stored prior to embedding in $2.5 \%$ glutaraldehyde in $100 \mathrm{mM} \mathrm{KH} \mathrm{KO}_{4}$ buffer, $\mathrm{pH} 6.8$, at $4^{\circ} \mathrm{C}$. Resin-embedded specimens were cut into 1 - to 2 - $\mu$ m-thick sections with a Leica Reichert Ultracut microtome (Leica Microsystems) and tungsten carbide knives (Delaware Diamond Knives, Wilmington, DE). The sections were stained with toluidine blue, air-dried, mounted, and observed with a light microscope (Zeiss AxioSkop Microscope; Carl Zeiss Jena GmbH, Zeiss Gruppe, Jena, Germany). A minimum of five resin-embedded pieces per selected internode were sectioned with the microtome.

\section{RESULTS}

The following descriptions represent the consensus of thousands of observations of hundreds of individual inoculated plants. 
There were two recognizable phases that occurred during the infection and colonization of wounded maize stalks by $C$. graminicola. A primary lesion formed at the wound site, which elongated by colonization of and expansion through the fibers associated with the vascular bundles and rind. Primary lesion development was followed by production of discontinuous secondary lesions at a distance from the wound site.

Primary lesion development. The development of lesions was monitored in living plants inoculated with fluorescent transgenic strains derived from the wild-type $C$. graminicola isolate (M1.001), the $C$. graminicola mutant (6-2), and the $C$. sublineolum control isolate ( $\mathrm{CgS11})$. The timing of the earliest stages of establishment of the fungi in maize stalks varied among replicate experiments. However, by 9 days after inoculation there were consistent and obvious quantitative differences between M1.001 and its fluorescent derivatives and the other strains (Fig. 1A and B). Statistical analysis revealed that transformation with fluorescent proteins had no significant effect on the virulence of CgS11 or 6-2 to maize stalks (measured as lesion length at $13 \mathrm{dpi}$ ) (Table 1), but caused a slight decrease in the virulence of M1.001 (Table 1). M1.001 and the fluorescent strains derived from it were all significantly more virulent than the CgSl1 or 6-2 strains (Table 1). All of the treatments produced lesions that were significantly larger than those resulting from the water control (Table 1).

The development of the lesion from a wound site inoculated with M1.001 or its fluorescent derivatives was primarily longitudinal (Fig. 1B). The fungus established within the wounded tissues and progressively colonized and destroyed the pith tissues (Figs. 2E to $\mathrm{G}$ and $3 \mathrm{G}$ to $\mathrm{I}$ ). This decay eventually resulted in the formation of an elongated primary lesion inside the stalk (Fig. 1C). Hyphae could sometimes be observed growing in the intercellular spaces within the primary lesion (Fig. 2K). The rind and the epidermal cell layer became desiccated, but remained intact above the disintegrated tissues at the center of the lesion

TABLE 1. Statistical analysis of lesion lengths caused by inoculation of wounded maize stalks by Colletotrichum strains

\begin{tabular}{lrcccc}
\hline Strain & $n$ & $\begin{array}{c}\text { Mean lesion } \\
\text { length }(\mathrm{cm})^{\mathrm{a}}\end{array}$ & $\begin{array}{c}\text { Standard } \\
\text { deviation }\end{array}$ & $\begin{array}{c}\text { LS } \\
\text { mean }^{\mathrm{b}}\end{array}$ & Class $^{\mathrm{c}}$ \\
\hline M1.001 & 9 & 4.52 & 1.61 & 4.08 & $\mathrm{a}$ \\
M1.001 GFP & 10 & 4.15 & 2.49 & 3.59 & $\mathrm{~b}$ \\
M1.001 ZsGreen & 12 & 4.14 & 2.15 & 3.68 & $\mathrm{~b}$ \\
6-2 & 7 & 1.40 & 0.40 & 1.10 & $\mathrm{c}$ \\
6-2 GFP & 7 & 1.47 & 0.73 & 1.20 & $\mathrm{c}$ \\
6-2 ZsGreen & 7 & 0.95 & 0.28 & 0.84 & $\mathrm{c}, \mathrm{d}$ \\
CgS11 & 9 & 0.89 & 0.31 & 1.01 & $\mathrm{c}, \mathrm{d}$ \\
CgS11 GFP1 & 7 & 0.87 & 0.32 & 0.64 & $\mathrm{~d}$ \\
CgS11 GFP2 & 7 & 1.04 & 0.31 & 0.69 & $\mathrm{~d}$ \\
Water & 9 & 0.25 & 0.16 & 0.23 & $\mathrm{e}$ \\
\hline
\end{tabular}

${ }^{a}$ Lesion lengths were measured at 13 days postinoculation (dpi). $n=$ total number of samples observed for each fungal strain at $13 \mathrm{dpi}$.

${ }^{b}$ LS means and classes were obtained using the GLM procedure that is part of the statistical analysis software (SAS Institute, Cary, NC) $(P<0.05)$ on the data collected 6 dpi up to 15 dpi.

${ }^{c}$ Strains with different letters are significantly different from one another using Tukey's means separation test with a significance level of $P<0.05$. (not shown). A broad darkly discolored zone surrounded the lesion (Fig. 1C). Fluorescent mycelium was visible in this zone, but never beyond it (Fig. 2A to D). Further observations of stained, embedded tissue sections confirmed that fungal hyphae were confined to the discolored areas (not shown). Falcate spores, together with setae, were produced on the surfaces of intact cells at the margins of the central lesion cavity (Fig. 1D), and also on aerial mycelium that traversed the spaces among the remaining vascular bundles within the cavity (not shown; Table 2). Oval spores were produced inside some of the parenchyma cells within the discolored lesion border (Fig. 2L; Table 2). In some cases, a few of the oval spores had germinated at the site of development (not shown). Fungal hyphae developed densely within the fiber cells beneath the rind (Fig. $2 \mathrm{H}$ to $\mathrm{J}$ ). This colonization was associated with a dark discoloration of the epidermis (Fig. 1A), and accumulation of thick-walled fungal material, that eventually became melanized (stromata), in the epidermal cells (Fig. 2M). Stromata were produced only in the discolored parts of the epidermis. Acervuli with setae and falcate spores were produced from these stromata if they were incubated in high humidity (not shown).

The development of the mutant $C$. graminicola strains and the C. sublineolum strains was qualitatively similar to that of M1.001. A primary lesion developed (Fig. 1E and F) in which falcate spores were produced. Oval spores were also produced in the discolored cell layers surrounding the lesions (Table 2). However, the size of the lesions, the frequency of colonization of the tissues surrounding the wounds, and the frequency of spore production were all substantially reduced in plants inoculated with the 6-2 or CgSl1 strains in comparison with plants inoculated with M1.001 strains (Tables 1 and 2). Very darkly discolored bundles that extended beyond the maximum extent of the lesion were observed accompanying $61 \%$ of lesions formed by the mutant strains, and $38 \%$ of the lesions formed by the nonpathogenic strains (Fig. $1 \mathrm{~F}$ and G). Similar discolored bundles were not observed associated with lesions produced by the M1.001 strains. Observations of sections of embedded tissue demonstrated that parenchyma cell walls appeared thicker in samples that had been wounded and treated with water than in samples from unwounded controls (Fig. $3 \mathrm{~A}$ to $\mathrm{F}$ ). Cell walls did not appear to be thicker than normal in regions surrounding primary lesions formed by M1.001 (Fig. 3G and I). In samples wounded and inoculated with $\mathrm{CgS11}$ or 6-2, the walls of cells surrounding the lesions did appear thickened, but cells containing fungal mycelium within the lesions appeared thinner-walled. In all inoculated tissues, numerous apparent occlusions were observed in the intercellular spaces (Fig. 3I to K). These occlusions were not observed in wounded tissues treated with water alone, or in unwounded tissues. Papillae similar to those observed in leaf cells undergoing $C$. graminicola infection (29) were not found in stalk samples.

Two types of hyphae were observed colonizing the parenchyma cells at the margins of primary lesions (Fig. 2N to P). Staining with acridine orange revealed that one hyphal type was multinucleate, with most of the cells $(89 \%)$ containing two nuclei (Fig. $2 \mathrm{~N}$ and $\mathrm{O}$ ). These hyphae were relatively thick, averaging $3.7( \pm 0.8) \mu \mathrm{m}$ in diameter. The second type was uniformly

TABLE 2. Incidence of primary (local) lesions and of the presence of oval or falcate spores in wounded maize stalks inoculated with Colletotrichum strains

\begin{tabular}{|c|c|c|c|c|c|c|}
\hline \multirow[b]{2}{*}{ Strain $^{\mathrm{a}}$} & \multicolumn{2}{|c|}{$\begin{array}{l}\text { Mycelium in necrotic parenchyma } \\
\text { cells (primary lesion) }\end{array}$} & \multicolumn{2}{|c|}{ Oval spores produced } & \multicolumn{2}{|c|}{ Falcate spores produced ${ }^{\mathrm{b}}$} \\
\hline & Total number of samples & Observed (\%) & Total number of samples & Observed (\%) & Total number of samples ${ }^{\mathrm{c}}$ & Observed (\%) \\
\hline $6-2$ & 88 & 81 & 88 & 7 & 179 & 21 \\
\hline CgSl1 & 79 & 60 & 79 & 3 & 193 & 30 \\
\hline
\end{tabular}

a The strain name refers to the strain together with its fluorescent derivatives.

b The data are expressed as percentages of stalks in which the event is observed.

c The total numbers of observations in this column are larger because falcate spores could be observed in stalks inoculated with the nonfluorescent strains. 

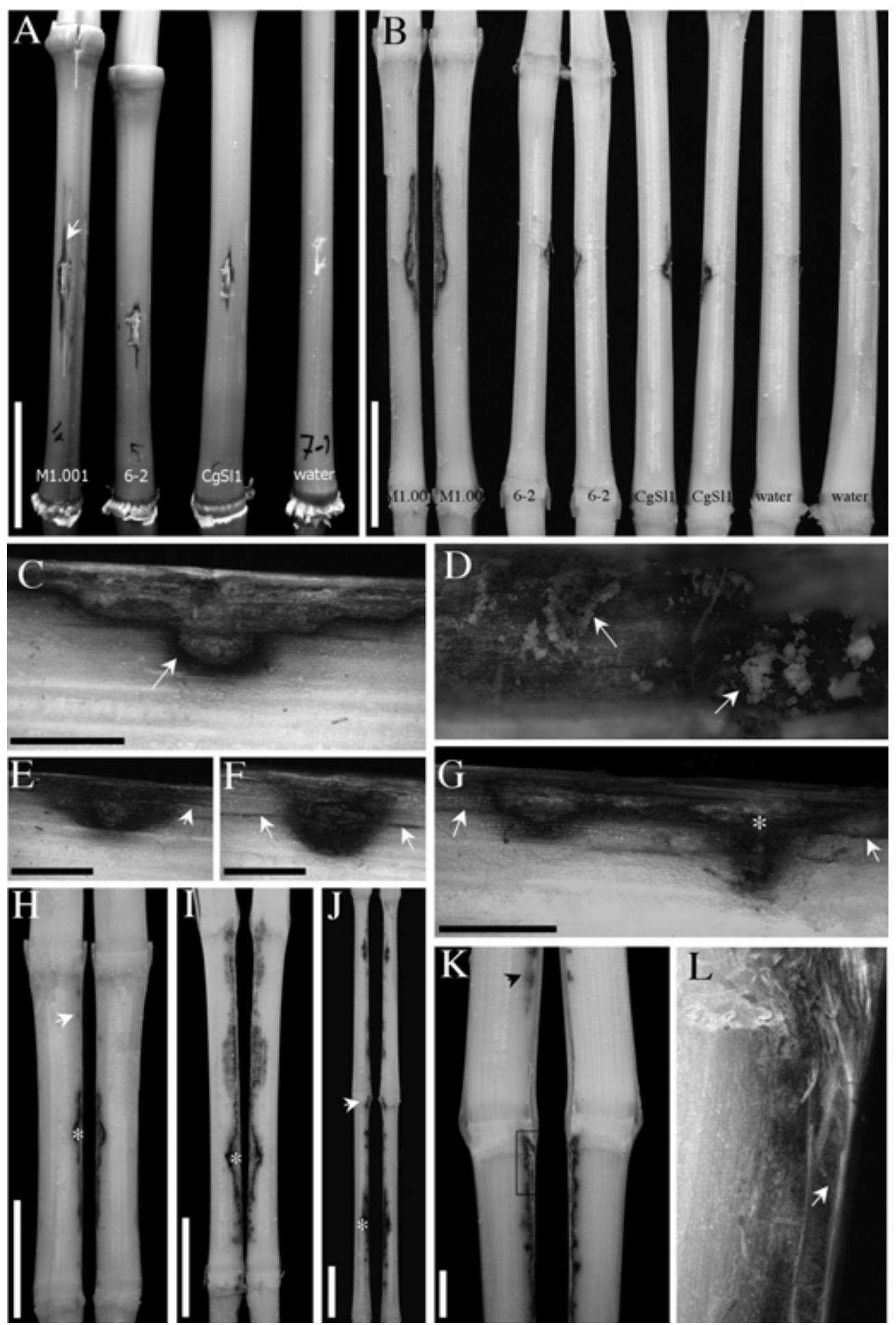

Fig. 1. Symptoms caused by inoculation of maize stalks with pathogenic, avirulent, and nonpathogenic strains of Colletotrichum spp. A, Typical external symptoms, 13 days postinoculation (dpi). Left to right: pathogenic C. graminicola strain M1.001, avirulent mutant strain 6-2, nonpathogenic C. sublineolum strain $\mathrm{CgS11}$, and water control. The arrow indicates an area containing abundant stromata in the epidermal cells. B, The same stalks as in $\mathbf{A}$, split in half with the longitudinal cut centered on the wound site and both halves shown. C, Closer view of a primary lesion formed by a pathogenic $C$. graminicola strain. The lesion was surrounded by a layer of dark parenchyma cells (arrow). The picture was taken 13 dpi with the green fluorescent protein (GFP) transformant of M1.001. D, Detailed view of acervuli (arrows) formed inside the primary lesion. This picture was taken 11 dpi with M1.001. E and F, Lesions formed by the avirulent mutant and the nonpathogenic $C$. sublineolum strains, respectively. The arrows indicate discolored bundles extending beyond the edges. These pictures were taken 11 dpi with the ZsGreen and GFP transformants of the mutant strain $(\mathbf{E})$ and the nonpathogenic strain $(\mathbf{F})$. G, Secondary infection foci formed by the avirulent mutant and nonpathogenic strains that were contiguous with the original lesion (the wound site is marked with an asterisk). This picture was taken 15 dpi with the avirulent mutant. H, Formation of small and lightly pigmented secondary lesions (arrow) in an internode inoculated with the ZsGreen transformant of M1.001 (the original wound site is indicated with an asterisk). This picture was taken $15 \mathrm{dpi}$. I, Larger, darkly pigmented secondary lesions containing green fluorescent fungal hyphae (not shown). This sample was observed 15 dpi with the ZsGreen transformant of M1.001 (the asterisk indicates the inoculation site). J, This sample was observed $15 \mathrm{dpi}$ with M1.001. Significant damage was visible at the node (arrow), which had apparently provided an opening for the pathogen to cross the node plate. K, Closer view of a "nodal breach". The cavity is surrounded by a layer of darkly pigmented cells. Note the presence of secondary lesions (black arrow) in the internode above. This picture was taken 12 dpi with M1.001. L, Detail of the cavity and the damage (black box in K) apparently caused by the fungus at the node plate. Aerial hyphae are visible in the cavity (arrow). Scale bars equal to $5 \mathrm{~cm}$ in $\mathbf{A}, \mathbf{B}, \mathbf{H}, \mathbf{I}$, and $\mathbf{J}, 0.5 \mathrm{~cm}$ in $\mathbf{C}, \mathbf{E}, \mathbf{F}$, and $\mathbf{G}$, and $1 \mathrm{~cm}$ in $\mathbf{K}$. 

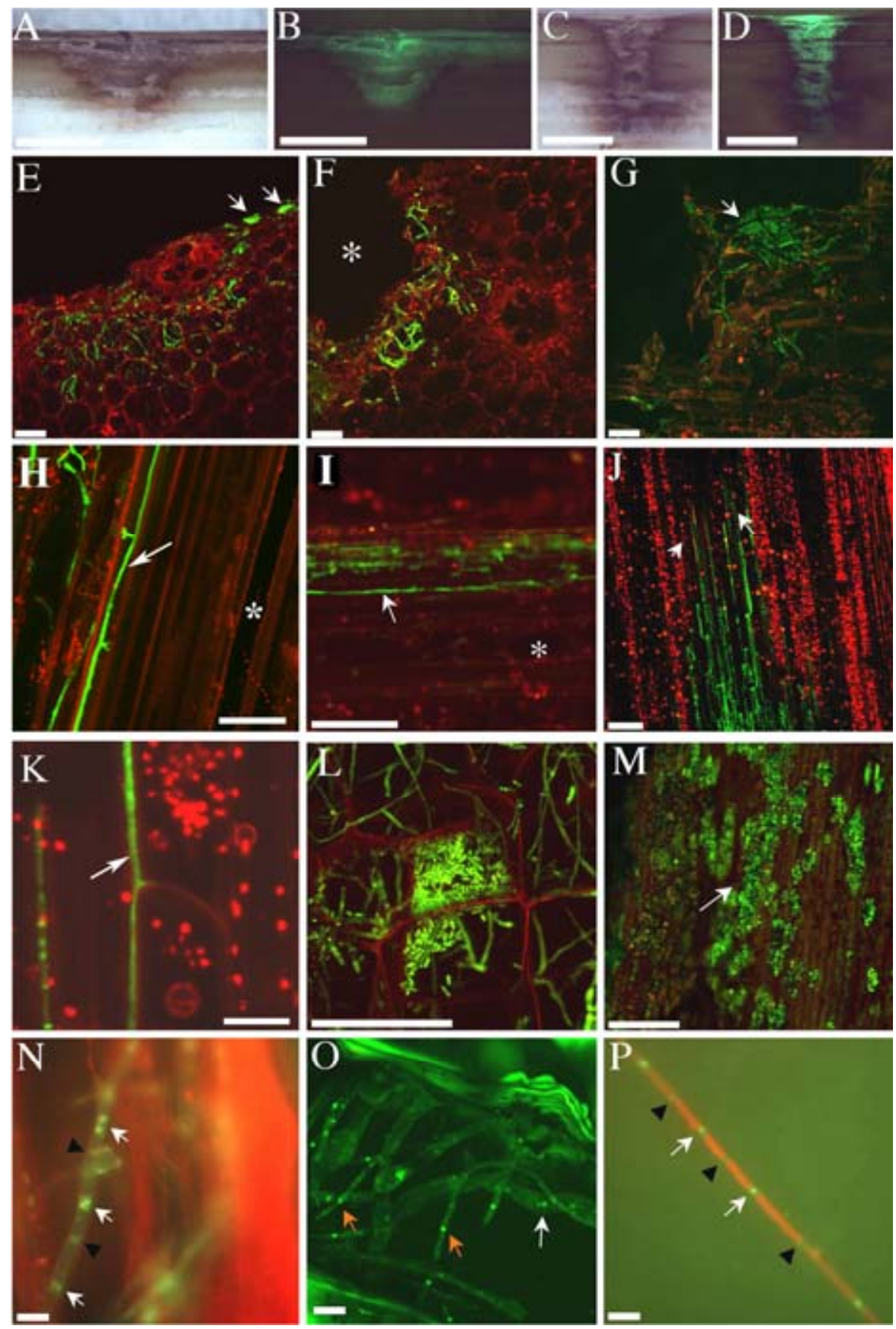

Fig. 2. Colletotrichum spp. colonizing living maize stalk tissues. A to D, Longitudinal median sections through primary lesions resulting from infection by the ZsGreen transformant of M1.001 (A and B) and ZsGreen transformants of the avirulent mutant strain 6-2 (C and D). Both samples were observed 8 days postinoculation (dpi). $\mathbf{E}$ to $\mathbf{G}$, Transverse sections through the margins of primary lesions. E, Colonization of the discolored parenchyma tissues at the lesion margin by M1.001 hyphae. The picture was taken $10 \mathrm{dpi}$ with the ZsGreen transformant of M1.001. The arrows indicate acervuli forming on the surface of the cells at the lesion margin. F, This picture was taken 6 dpi with the ZsGreen transformant of the avirulent mutant strain. The asterisk indicates the site of the original wound. Fungal hyphae have colonized the parenchyma cells that have been damaged directly by the wound. G, This picture was taken 13 dpi with one of the GFP transformants of the nonpathogenic $C$. sublineolum strain. Fungal mycelium has colonized host parenchyma cells to a very limited extend. The arrow indicates an acervulus with setae on the surface of the colonized tissues. $\mathbf{H}$ to $\mathbf{J}$, Colonization of fibers and bundle tissues by pathogenic $C$. graminicola strains. $\mathbf{H}$, Section from the edge of a lesion, in which hyphae (arrow) can be seen colonizing a bundle fiber. The asterisk indicates the xylem. This picture was taken 14 dpi with the GFP transformant of M1.001. I, Section from the edge of a lesion, in which a hypha (arrow) can be seen colonizing a bundle fiber. This picture was taken 11 dpi with the ZsGreen transformant of M1.001. The asterisk indicates the xylem. J, Hyphae (arrow) colonizing fibers in the rind. This view is of uncut tissue, through the epidermal cells into the fibers below. The picture was taken 11 dpi with the ZsGreen transformant of M1.001, at the apex of the external lesion. K, Colonization of a bundle fiber (hypha indicated by arrow) at the edge of a primary lesion resulting from infection with the avirulent mutant. This picture was taken 12 dpi with the ZsGreen transformant of the mutant strain. L, Production of oval spores by the pathogenic strain in parenchyma cells. This picture was taken 8 dpi with the ZsGreen transformant of M1.001. M, Stromata (arrow) produced by the pathogenic strain in colonized epidermal cells. This picture was taken 13 dpi with the ZsGreen transformant of M1.001. The samples in $\mathbf{N}$ to $\mathbf{P}$ were stained with acridine orange. $\mathbf{N}$, Thick, multinucleate hypha colonizing parenchyma cells at the margin of a primary lesion. The black arrows indicate septa, and white arrows indicate nuclei. This picture was taken 8 dpi with M1.001. O, An intact parenchyma cell at the edge of a primary lesion colonized by both types of hyphae. The white arrows indicate multiple nuclei per cell in the thicker hyphae, and the orange arrows indicate single nuclei in the thinner hyphae. The layered structure that is fluorescing green at the top of the picture is the plant cell wall. This picture was taken 7 dpi with M1.001. P, A thin, monokaryotic hypha located outside the host cells, within the disintegrated center of a primary lesion. The black arrows indicate septa, the white arrows show the nuclei. The picture was taken 8 dpi with M1.001. Scale bars are equal to $0.5 \mathrm{~cm} \mathrm{in} \mathbf{A}, \mathbf{B}, \mathbf{C}$, and $\mathbf{D}, 100 \mu \mathrm{m}$ in $\mathbf{E}, \mathbf{F}, \mathbf{G}$, $\mathbf{H}, \mathbf{I}, \mathbf{J}, \mathbf{K}, \mathbf{L}$, and $\mathbf{M}$, and $10 \mu \mathrm{m}$ in $\mathbf{N}, \mathbf{O}$, and $\mathbf{P}$ 

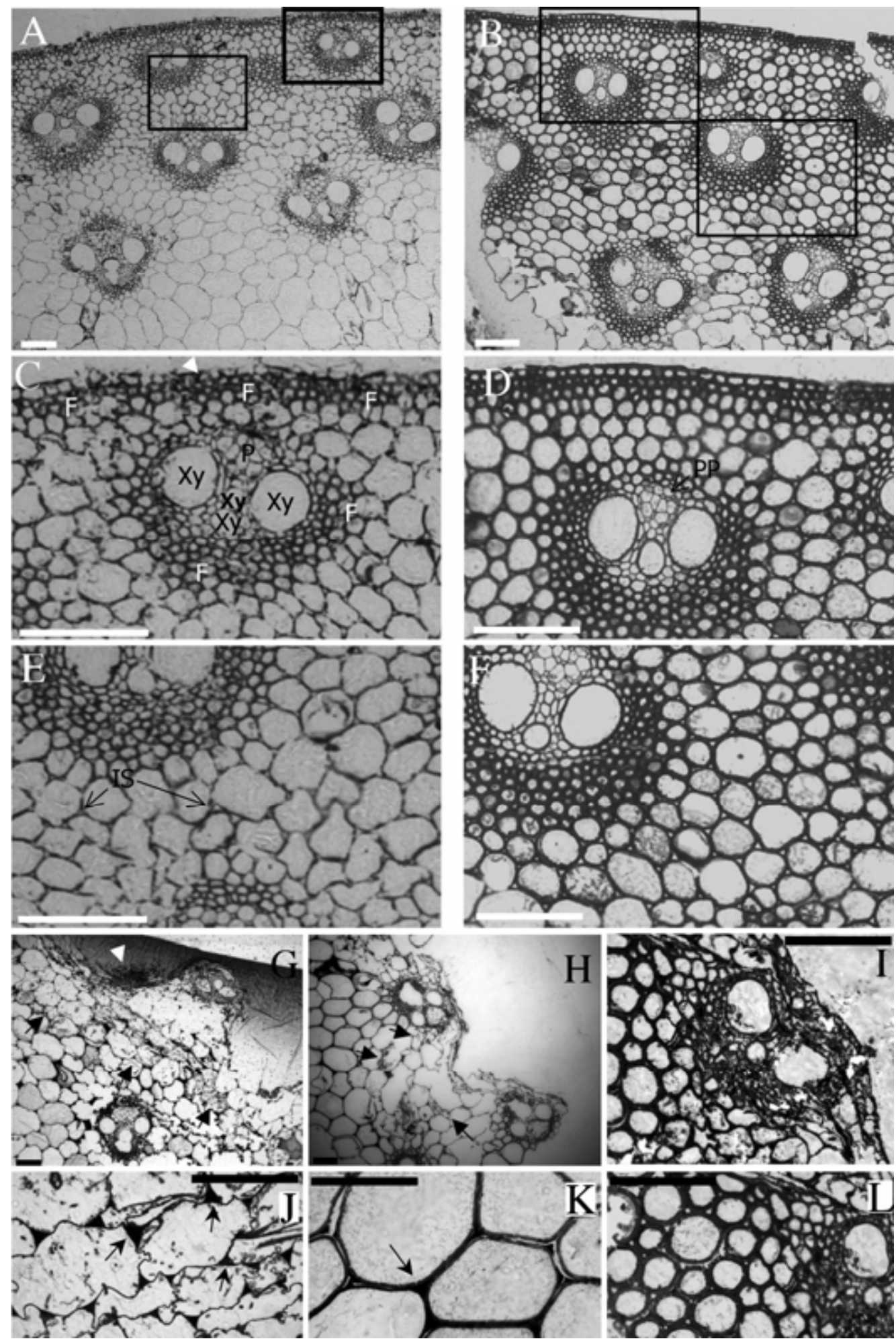

Fig. 3. Thick sections of embedded maize stalk tissues. A, Transverse section demonstrating the normal organization and appearance of unwounded, uninoculated maize stalk tissue, including the rind, vascular bundles, and pith (parenchyma cells). B, Transverse section of maize stalk tissues 7 days after wounding with a dissecting needle. C, A closer view of a typical vascular bundle in the unwounded maize stalk (detail from A, upper rectangle). Cell types include fibers (F) forming the bundle sheath, xylem vessels (Xy), and phloem (P). Fibers (F) are also present in the rind just below the epidermis (arrow). D, A closer view of a vascular bundle in the wounded maize stalk (detail from $\mathbf{B}$, upper rectangle) (PP, primary phloem). $\mathbf{E}$, A closer view of healthy parenchyma cells (detail from $\mathbf{A}$, bottom rectangle). Note the relatively thin walls, and the clear intercellular spaces (IS). F, A closer view of the thick-walled parenchyma cells near the wound (detail from B, lower rectangle). Compare to E. G to I, Stalks wounded and inoculated with the pathogenic $C$. graminicola strain, the avirulent mutant strain, and the nonpathogenic $C$. sublineolum strain, respectively. G, Transverse section from the lower edge of a primary lesion. The white arrow indicates an acervulus. There are numerous hyphae visible in the cells (black arrows). The intercellular spaces between the parenchyma cells are often filled with dark occlusions, magnified in $\mathbf{J}$ (J, black arrows). Cell walls do not appear to be very thick (compare with $\mathbf{B}, \mathbf{C}$, and $\mathbf{F}$ ). The sample was collected 9 dpi with the green fluorescent protein (GFP) transformant of M1.001. H, Transverse section from the lower edge of a primary lesion resulting from infection by the avirulent mutant, 9 dpi. Walls of the parenchyma cells surrounding the primary lesion (magnified in $\mathbf{K}$ ) are quite thick. Intercellular spaces were filled with dense occlusions (K, black arrow). Hyphae were only visible in a few cells nearest to the wound site (H, black arrows). I, Transverse section from the lower edge of a primary lesion resulting from inoculation with the nonpathogenic $C$. sublineolum strain, magnified in $\mathbf{L}$. This sample was collected $7 \mathrm{dpi}$ with $\mathrm{CgSl}$. Scale bars $=100 \mu \mathrm{m}$. 

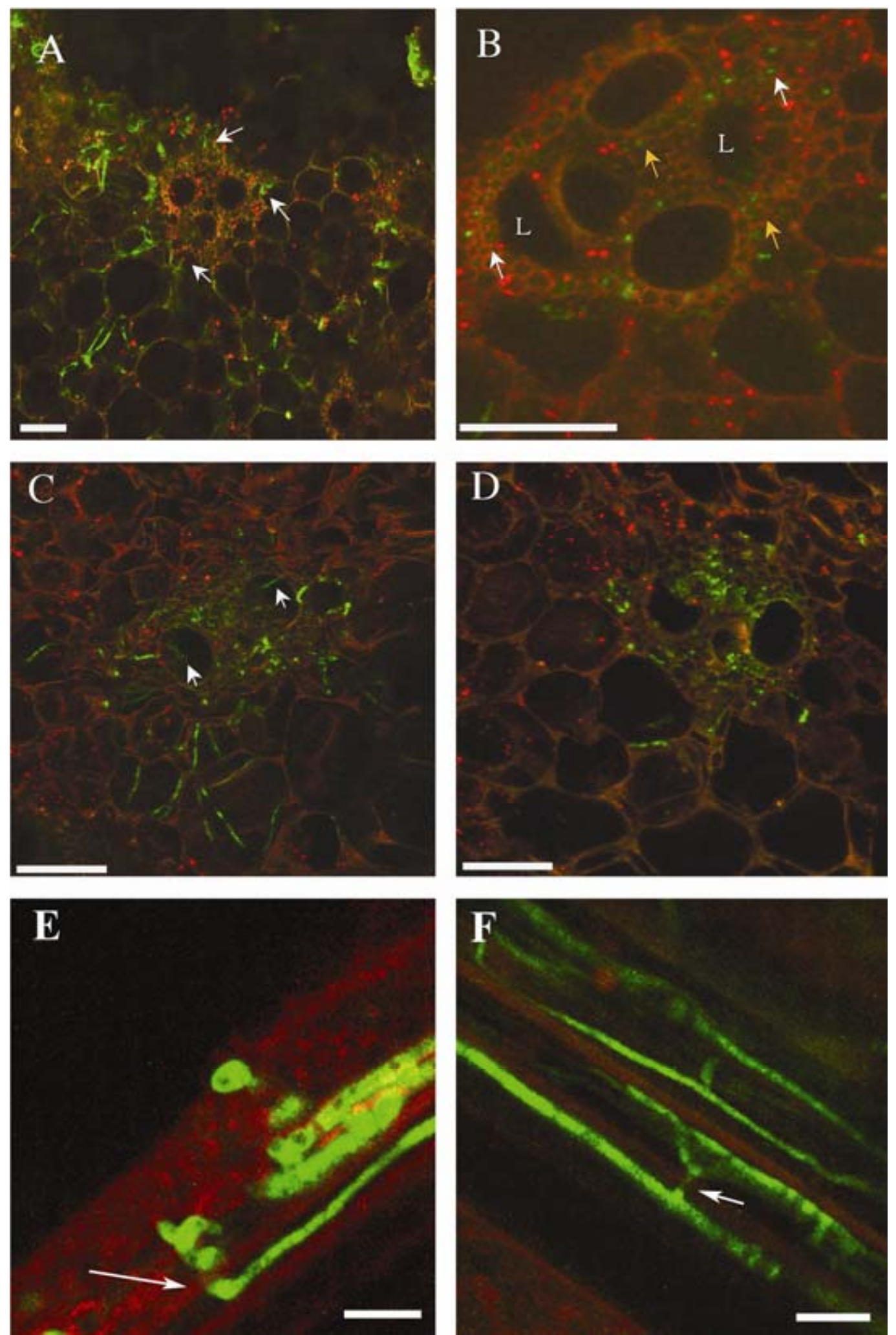

Fig. 4. Colonization of bundle fibers. A and B, Transverse sections through the edges of the discolored cell layers surrounding primary lesions resulting from inoculation with the pathogenic $C$. graminicola strains. A, Hyphae are visible inside several fibers surrounding this bundle. Hyphae appear to have emerged from the fibers to colonize the surrounding parenchyma cells (white arrows). B, A view of a colonized bundle at the edge of the primary lesion. Numerous hyphae are visible in the fibers (white arrows), and some hyphae are also visible in tracheids near the center of the bundle (orange arrows). The large xylem vessels do not appear to be colonized. L: lacunas. Pictures A and B were both taken 8 days postinoculation (dpi) with the ZsGreen transformant of M1.001. C and D, Apparent early stages in the formation of a secondary lesion. The pictures are of two adjoining sections from the same discolored bundle just beyond the edge of a primary lesion. The section in $\mathbf{C}$ was closer to the primary lesion than the section in $\mathbf{D}$. These pictures were taken $8 \mathrm{dpi}$ with the ZsGreen transformant of M1.001. $\mathbf{C}$, This part of the bundle is quite heavily colonized. Proliferation into the adjacent parenchyma tissues has apparently just begun. The large xylem vessels contain hyphae (white arrows). D, In this section, the fibers are densely colonized but not the large xylem vessels. E, Hypha apparently in the process of "breaking out" of a fiber (below) into adjacent parenchyma cells (arrow). This sample was observed 9 dpi with the green fluorescent protein (GFP) strain of M1.001. F, The hyphae emerge from the fibers via narrow extensions (arrows) that may be passing though pits. This sample was observed 9 dpi with the GFP strain of M1.001. Scale bars are equal to $100 \mu \mathrm{m}$ in $\mathbf{A}$ to $\mathbf{D}$ and $10 \mu \mathrm{m}$ in $\mathbf{E}$ and $\mathbf{F}$. 
monokaryotic and noticeably thinner, averaging only $1.9( \pm 0.6)$ $\mu \mathrm{m}$ in diameter (Fig. $2 \mathrm{O}$ and P). Aerial hyphae traversing the spaces within the disintegrated centers of the lesions were all of the thinner, mononucleate type: the thicker, multinucleate hyphae were not observed outside host cells. Thicker hyphae were frequently observed in fibers (Figs. $2 \mathrm{H}$ and $4 \mathrm{E}$ and $\mathrm{F}$ ), but nuclear condition could not be discerned in these cases: perhaps acridine orange failed to penetrate these highly lignified tissues.

Longitudinal development of the pathogen in the maize stalk. By 6 dpi, the C. graminicola M1.001 strains had heavily colonized the lignified fibers beneath the rind and surrounding the vascular tissues within the primary lesion (Figs. 2 and 4). The fungus progressed longitudinally in the stalk by growing through these cells. Formation of secondary lesions was frequently observed at some distance from the primary lesion (Fig. $1 \mathrm{H}$ and I; Table 3). The presence of these secondary lesions was sometimes, but not always, associated with dark rind discoloration. Secondary lesions were only formed along the same side of the stalk as the original wound (Fig. 1I) and were associated with bundles that were linked to the primary lesion at the wound site. Two types of secondary lesions could be recognized. The first was relatively small and light brown (Fig. 1H) and contained no fluorescent hyphae. The second type was larger and darker in color (Fig. 1I) and contained fluorescent fungal material (Table 3). Hyphae were observed apparently emerging from colonized fibers within the vascular bundles or beneath the rind and giving rise to this second

type of secondary lesion (Fig. 4A to F). At the point of emergence, the hyphae were narrow and seemed to be passing through very small openings, possibly pits, in the walls of the fiber cells (Fig. 4F). The primary lesion at the wound site and the secondary lesions eventually merged, and in this way the entire internode could become rotted within only 2 weeks after inoculation.

Fungal hyphae were sometimes seen within xylem elements and other vascular tissues (Fig. 4B to D). However, only vessels directly damaged by the wound or by the subsequent degradation in the primary lesion were ever colonized. Bundle fiber cells were always colonized before xylem or phloem, and xylem or phloem colonization only occurred in areas that were already significantly degraded, whereas fiber colonization occurred ahead of significant damage to the tissues. Oval spores were observed only once inside the xylem vessels, just below a nodal plate, where at least one of them had germinated (not shown).

When the fungus reached the node, mycelium proliferated in the parenchyma cells just below it, and this was accompanied by a dark discoloration of the plant tissues (Table 3) and formation of secondary lesions (Fig. 1I and $\mathrm{K}$ to $\mathrm{L}$ ). On several occasions, the fungus progressed beyond the node into the internode above (Fig. $1 \mathrm{~J}$ to L; Table 3). Movement into the upper internode appeared to result after a breakdown of tissues at the nodal plate, causing a breach that allowed the fungus to pass through via the disintegrated cells (Fig. 1K and L). Secondary lesions were formed in the upper internode (Fig. 1K) and fluorescent fungal hyphae were observed in some of these lesions (Table 3). Very rarely, the fungus also spread downward through the lower node and formed secondary lesions in the internode below (Table 3).

In contrast to M1.001, spread of the mutant $C$. graminicola and the $C$. sublineolum strains through the maize stalk was extremely limited. These strains colonized fibers under the rind and along bundles within the primary lesion, but to a much more limited extent than M1.001 (Fig. 2K). Vascular bundles containing fibers colonized by the mutant or $C$. sublineolum strains often exhibited a very dark discoloration (Fig. 1E to G; Table 3). Discontinuous secondary lesions were never observed with either strain, but occasionally new disease foci formed that were contiguous with the original lesion (Fig. 1G; Table 3).

\section{DISCUSSION}

To our knowledge, this is the first detailed cytological study of the colonization of living maize stalks by $C$. graminicola. Experiments were performed in the greenhouse due to the necessity for containment of the transgenic fungal strains. The general course of symptom development in the hybrid Jubilee was similar to descriptions of disease progress on highly susceptible maize genotypes in the field (44). It also matches descriptions of anthracnose stalk rot disease progress in the susceptible dent corn inbred B73 in the greenhouse (38). However, because of the constraints of our experimental design, we looked only at infection of green maize stalks inoculated prior to anthesis. In the field, anthracnose stalk rot is also often a problem on older, senescing stalks, and the process of colonization in senescing stalks could differ from our observations reported here. Furthermore, Jubilee is a highly susceptible cultivar of sweet corn, and for these experiments it was grown under relatively low light intensity conditions that are likely to increase susceptibility to anthracnose stalk rot (15). Thus, it will be important to confirm these observations with other maize genotypes and under other conditions to determine how generally they apply.

For these experiments, a small wound was created to allow fungal ingress. There is an established relationship between wounding caused by insects such as the European corn borer and the incidence of anthracnose stalk rot and other stalk rot diseases $(6,7)$. Although the pathogen can directly infect and colonize unwounded stalks (45; C. Venard, unpublished data), the results of our experiments with intact stalks were relatively inconsistent, and so we included wounding as part of our inoculation protocol for this work.

C. graminicola is a hemibiotroph in leaves $(29,35)$. In wounded stalks, we noted the presence of thick, multinucleate hyphae apparently giving rise to thinner, mononucleate hyphae within parenchyma cells at the edges of the primary lesions. This hyphal dimorphism is reminiscent of C. graminicola in leaves (29), and of hemibiotrophy in other Colletotrichum species (33).

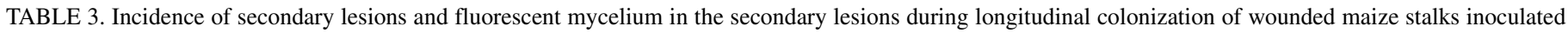
with Colletotrichum strains

\begin{tabular}{|c|c|c|c|c|c|c|c|}
\hline \multirow[b]{2}{*}{ Strain ${ }^{\mathrm{a}}$} & \multicolumn{4}{|c|}{ Presence of secondary lesions ${ }^{b}$} & \multicolumn{3}{|c|}{ Fluorescent mycelium in the secondary lesions } \\
\hline & $\begin{array}{c}\text { Total number } \\
\text { of samples }\end{array}$ & $\begin{array}{c}\text { Inoculated } \\
\text { internode }(\%)\end{array}$ & $\begin{array}{l}\text { Internode } \\
\text { above }(\%)\end{array}$ & $\begin{array}{l}\text { Internode } \\
\text { below }(\%)\end{array}$ & $\begin{array}{l}\text { Total number } \\
\text { of samples }\end{array}$ & $\begin{array}{c}\text { Inoculated } \\
\text { internode }(\%)\end{array}$ & $\begin{array}{l}\text { Internode } \\
\text { above }(\%)\end{array}$ \\
\hline M1.001 & 235 & 25 & 9 & 3 & 52 & 60 & $60^{c}$ \\
\hline $6-2$ & 173 & 8 & 0 & 0 & 4 & 75 & $\mathrm{NA}^{\mathrm{d}}$ \\
\hline CgS11 & 193 & 3 & 0 & 0 & 1 & 100 & NA \\
\hline
\end{tabular}

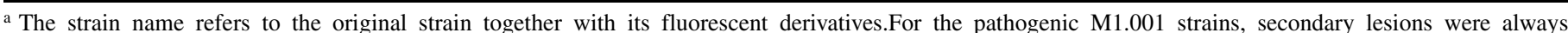
discontinuous with the primary lesion at the wound site. For the 6-2 and CgS11 strains, secondary lesions were always continuous with the primary lesion.

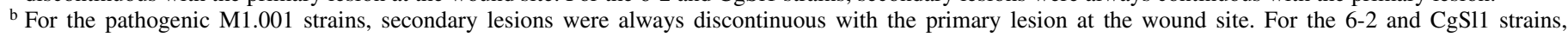
secondary.

c This percentage is from a total of only five samples that had secondary lesions in the internode above.

d Not applicable, since for these strains there were no secondary lesions formed in the internode above. 
However, morphology alone does not prove that the thicker hyphae are biotrophic. More evidence supporting the idea that stalk colonization occurs hemibiotrophically is described in the report of Tang et al. (38) in which parenchyma cells containing C. graminicola hyphae within the secondary lesions were capable of plasmolysis.

The mutant strain of $C$. graminicola was included in this study so that we could compare a compatible and an incompatible interaction in a single maize genotype. The mutation in strain 6-2 affects a gene that encodes a component of the microsomal signal peptidase, and thus is likely to affect protein transport and secretion (40). It was rather surprising that the $C$. graminicola mutant and $C$. sublineolum strains were both able to complete their life cycles on wounded maize stalks, since neither of these strains sporulates on living maize leaves (29). However, although the lesions were qualitatively similar, lesion expansion was significantly reduced for both strains in comparison with the wild-type C. graminicola strains. Thus, resistance to both of these strains in wounded Jubilee stalks is quantitative rather than qualitative.

The lesions formed by all of the strains were surrounded by broad zones of darkly discolored parenchyma cells. This discoloration may have been the result of an active defense mechanism in the plant cells, since it was not observed in inoculated detached stalk pieces (C. Venard, unpublished data). Another possible sign of an active host defense response was thickening of the walls of cells surrounding the wound site. Wall thickening due to deposition of lignin is a general wound and stress response in monocots (43). Lignin production occurs via the phenylpropanoid pathway, which is also responsible for production of other defense metabolites that appear to play a role in the anthracnose disease $(8,21,27,43)$. The precise biochemical nature of the cell wall thickening we observed in our study requires further study. It is possible that wound-healing, a phenomenon in which wounded stalks become increasingly resistant to infection by $C$. graminicola with time, may be associated with this response $(8,30,31)$.

Anthracnose stalk rot and top dieback in the field are frequently associated with vascular discoloration $(8,31)$. We observed relatively little discoloration in our experiments, except for darkening of bundles immediately adjacent to lesions caused by the avirulent or nonpathogenic strains. Light brown discolorations observed along vascular bundles at a distance from primary lesions caused by M1.001 did not appear to contain fungal material, suggesting the presence of a transported signal or toxin. C. acutatum is known to produce compounds that are toxic to several plant species including Cacao and Polyathia spp. (23). Because bundle discoloration appeared to precede fungal spread through the fibers and emergence into the adjoining parenchyma cells, it is possible that it is a prerequisite for the formation of secondary lesions.

It has been reported that $C$. graminicola can be recovered from isolated vascular bundles (8). Because oval spores have reportedly been observed inside xylem, it was hypothesized that $C$. graminicola moves systemically primarily as oval spores through the xylem vessels. It was also suggested that the oval spores would be trapped at nodes and form new colonies at those sites that could spread the disease into the next internode $(8,34)$. Although C. graminicola certainly used bundle tissues for rapid spread through the internode, we found that it spread primarily as hyphae within the mostly nonliving fiber cells. New disease foci (secondary lesions) were apparently formed when the fungus emerged from the fibers in both the bundles and the rind at intervals and began to attack adjacent cells. The ability to establish in the fiber cells and to move from fiber to fiber both along the vascular bundle and beneath the rind were negatively affected in the mutant 6-2 and in the $C$. sublineolum strains.

Fungal progression was usually stopped at the node. The vascular organization in the nodes is extremely complex. Vascular bundles are discontinuous at this point, a feature that limits the impact of damage to the vascular system in one internode, and blocks the movement of large pathogens, including fungal spores, in the sap (36). Occasionally, the fungus was able to enter the upper internode beyond the node. This resulted after significant degradation of parenchyma cells at the nodal plate, causing a breach in the node through which the fungus could penetrate. It seems likely that such breaches would be common, given enough time, and this is probably the major way in which the fungus progresses between internodes.

Our study has not clarified the role of the oval spores in the disease cycle of $C$. graminicola. Oval spores may be involved in systemic movement in some cases, but the primary way that we observed $C$. graminicola moving through the stalk is as hyphae in the fibers. Oval spores were only observed once within the xylem elements of the stalks in our experiments. In that case it appeared that the spores had collected below the nodal plate, and at least one had germinated and seemed to be in the process of initiating a new disease focus. Thus, it is possible that oval spores do play some role in spreading the pathogen within the stalks. However, because they appear to be produced primarily in parenchyma cells, it is likely that the stalks would have to be thoroughly macerated before the spores would be released, and then there is the question of how they could be carried passively upward once the flow within the xylem had been broken in the degraded vessels. Falcate conidia were also produced abundantly in primary lesions. Production of falcate spores is dependent on light and high humidity (34). Presumably, the rind covering the incubation chamber maintains the necessary humidity, and also allows enough light penetration to induce the spores. Because both types of spores are produced in these wound sites, it is possible that they could be picked up on or in the bodies of insects feeding at these sites and vectored to new wounds on other plants. It is known that spores of this pathogen retain viability after passing through the gut of the European corn borer (8).

Our study has revealed that $C$. graminicola is an extremely efficient colonizer of fiber cells within the maize plant beneath the rind and in association with vascular bundles. Using these cells, it moves rapidly through the internode from an initial inoculation point. We suggest that fiber colonization is a way for the pathogen to move behind enemy lines. The plant appears to set up a defensive perimeter, visible as discolored cells with thickened cell walls, surrounding the primary lesion. However, the mostly nonliving fibers may be left relatively unguarded, so that if the pathogen can move through the defensive line by this route, it can break out in a new area and begin the process of degradation again. As a potentially important pathogenicity determinant, fiber colonization by $C$. graminicola deserves further study.

\section{ACKNOWLEDGMENTS}

We thank E. Nuckles and D. Brown for excellent technical assistance; R. Howard and A. Da Silva Conceicao (DuPont), and M. Goodin and J. Kroemer (University of Kentucky) for helpful microscopy advice; S. McClintock (University of Kentucky, Department of Statistics) for the statistical analysis; J. Flowers for her guidance in the embedding experiments and the Agrobacterium-mediated mutagenesis protocol; R. O'Connell (Max Plank Institute for Plant Breeding Research, Köln, Germany) and B. Dumas (Pole de Biotechnologie Vegetale, Castanet-Tolosan, France) for sharing the pBin-GFP-hph plasmid; J. Sweigard (DuPont) for providing us with the pSM615 and pSM611 plasmids; and R. Howard for his critical reading of our manuscript. We acknowledge and appreciate the financial support of the DuPont-de Nemours Company. This is paper 07-12-10 from the Kentucky Agricultural Experiment Station, published with the permission of the Director.

\section{LITERATURE CITED}

1. Anderson, B., and White, D. G. 1987. Fungi associated with cornstalks in Illinois in 1982 and 1983. Plant Dis. 71:135-137. 
2. Anderson, B., and White, D. G. 1994. Evaluation of methods for identification of corn genotypes with stalk rot and lodging resistance. Plant Dis. 78:590-593.

3. Badu-Apraku, B., Gracen, V. E., and Bergstrom, G. C. 1987. A major gene for resistance to anthracnose stalk rot in maize. Phytopathology 77:957-959.

4. Badu-Apraku, B., Gracen, V. E., and Bergstrom, G. C. 1987. A major gene for resistance to anthracnose leaf blight in maize. Plant Breed. 98:194-199.

5. Bergstrom, F. B., and Bergstrom, G. C. 1987. Influence of maize growth stage on fungal movement, viability, and rot induction in stalk inoculated with Colletotrichum graminicola. (Abstr.) Phytopathology 77:115.

6. Bergstrom, G. C., Croskey, B. S., and Carruthers, R. I. 1983. Synergism between Colletotrichum graminicola and the European corn borer in stalk rot of corn in New York. (Abstr.) Phytopathology 73:842.

7. Bergstrom, G. C., Davis, P. M., and Waldron, J. K. 1997. Management of anthracnose stalk rot/European corn borer pest complex with transgenic Bt corn hybrids for silage production. Biol. Cultural Tests 12:13.

8. Bergstrom, G. C., and Nicholson, R. L. 1999. The biology of corn anthracnose-knowledge to exploit for improved management. Plant Dis. 83:596-608.

9. Bourett, T. M., Sweigard, J. A., Czymmek, K. J., Carroll, A., and Howard, R. J. 2002. Reef coral fluorescent proteins for visualizing fungal pathogens. Fungal Genet. Biol. 37:211-220.

10. Byrnes, K. J., and Carroll, L. B. 1986. Fungi causing stalk rot of conventional-tillage and non-conventional tillage corn in Delaware. Plant Dis. 70:238-239.

11. Callaway, M. B., Smith, M. E., and Coffman, W. R. 1992. Effect of anthracnose stalk rot on grain yield and related traits on maize adapted to the northeastern United States. Can. J. Plant Sci. 72:1031-1036.

12. Carson, M. L., and Hooker, A. L. 1980. Inheritance of resistance to anthracnose leaf blight in five inbred lines of corn. Phytopathology 71:488-491.

13. Carson, M. L., and Hooker, A. L. 1981. Inheritance of resistance to stalk rot caused by Colletotrichum graminicola. Phytopathology 71:1190-1196.

14. Dale, J. L. 1963. Corn anthracnose. Plant Dis. Rep. 47:245-249.

15. Dodd, J. L. 1980. The role of plant stresses in development of corn stalk rots. Plant Dis. 64:533-537.

16. Flowers, J. L., and Vaillancourt, L. J. 2005. Parameters affecting the efficiency of Agrobacterium tumefaciens-mediated transformation of Colletotrichum graminicola. Curr. Genet. 48:380-388.

17. Forgey, W. M., Blanco, M. H., and Loegoring, W. Q. 1978. Differences in pathological capabilities and host specificity of Colletotrichum graminicola on Zea mays. Plant Dis. Rep. 62:573-576.

18. Gatch, E. W., and Munkvold, G. P. 2002. A comparison of maize stalk rot occurrence in Bt and non-Bt hybrids. Plant Dis. 86:1149-1155.

19. Gatch, E. W., and Munkvold, G. P. 2002. Fungal species composition in maize stalks in relation to European corn borer injury and transgenic insect protection. Plant Dis. 86:1156-1162.

20. Guenther, J. C., and Trail, F. 2005. The development and differentiation of Gibberella zeae (anamorph: Fusarium graminearum) during colonization of wheat. Mycologia 97:229-237.

21. Hipskind, J., Wood, K., and Nicholson, R. L. 1996. Localized stimulation of anthocyanin accumulation and delineation of pathogen ingress in maize genetically resistant to Bipolaris maydis race O. Physiol. Mol. Plant Pathol. 49:247-256.

22. Hooker, A. L., and White, D. G. 1976. Prevalence of corn stalk rot disease in Illinois. Plant Dis. Rep. 60:1032-1034.

23. Jayashinge, C. K., and Fernando, T. H. 2001. Toxic activity from liquid culture of Colletotrichum acutatum. Mycopathologia 152:97-101.

24. Keller, N. P., and Bergstrom, G. C. 1988. Developmental predisposition of maize anthracnose stalk rot. Plant Dis. 72:977-980.

25. Leonard, K. J., and Thompson, D. L. 1976. Effect of temperature and host maturity on lesion development of Colletotrichum graminicola on corn. Phytopathology 66:635-639.

26. Lorang, J. M., Tuori, R. P., Martinez, J. P., Sawyer, T. L., Redman, R. S.,
Rollins, J. A., Wolpert, T. J., Johnson, K. B., Rodriguez, R. J., Dickman, M. B., and Ciuffetti, L. M. 2001 Green fluorescent protein is lighting up fungal biology. Appl. Environ. Microbiol. 67:1987-1994.

27. Lyons, P. C., Wood, K. V., and Nicholson, R. L. 1990. Caffeoyl ester accumulation in corn leaves inoculated with fungal pathogens. Phytochemistry 29:97-101.

28. Mduruma, Z. O. 1984. Breeding for resistance to Colletotrichum graminicola (Ces.) Wils. in corn, Zea mays L. M.Sc. thesis. Cornell University, NY.

29. Mims, C. W., and Vaillancourt, L. J. 2002. Ultrastructural characterization of infection and colonization of maize leaves by Colletotrichum graminicola, and by $C$. graminicola pathogenicity mutant. Phytopathology 92:803-812.

30. Muimba-Kankolongo, A., and Bergstrom, G. C. 1990. Transitory wound predisposition of maize to anthracnose stalk rot. Can. J. Plant Pathol. 12:1-10.

31. Muimba-Kankolongo, A., and Bergstrom, G. C. 1992. Wound predisposition of maize to anthracnose stalk rot as affected by internode position and inoculum concentration of Colletotrichum graminicola. Plant Dis. 76:188-195.

32. O'Connell, R., Herbert, C., Sreenivasaprasad, S., Khatib, M., EsquerreTugaye, M.-T., and Dumas, B. 2004. A novel Arabidopsis-Colletotrichum pathosystem for the molecular dissection of plant-fungal interactions. Mol. Plant-Microbe Interact. 17:272-282.

33. O’Connell, R., Perfect, S., Hughes, B., Carzaniga, R., Bailey, J., and Green, J. 2000. Dissecting the cell biology of Colletotrichum infection processes. Pages 57-77 in: Colletotrichum Host Specificity, Pathology, and Host-Pathogen Interaction. D. Prusky, S. Freeman, and M. Dickman, eds. The American Phytopathological Society, St. Paul, MN.

34. Panaccione, D. G., Vaillancourt, L. J., and Hanau, R. M. 1989. Conidial dimorphism in Colletotrichum graminicola. Mycologia 81:876883.

35. Politis, D. J., and Wheeler, H. 1973. Ultrastructural study of penetration of maize leaves by Colletotrichum graminicola. Physiol. Plant Pathol. $3: 465-471$

36. Shane, M. W., MacCully, M. E., and Canny, M. J. 2000. The vascular system of the maize stem revisited: Implications for water transport and xylem safety. Ann. Bot. 86:245-58.

37. Spurr, A. R. 1969. A low-viscosity epoxy resin embedding medium for electron microscopy. J. Ultrastructure Res. 26:31-43.

38. Tang, W., Coughlan, S., Crane, E., Beaty, M., and Duvick, J. 2006. The application of laser microdissection to in planta gene expression profiling of the maize anthracnose stalk rot fungus Colletotrichum graminicola. Mol. Plant-Microbe Interact. 19:1240-1250.

39. Thon, M. R., Nuckles, E. M., Takach, J. E., and Vaillancourt, L. J. 2002 CPR1: A gene encoding a putative signal peptidase that functions in pathogenicity of Colletotrichum graminicola to maize. Mol. PlantMicrobe Interact. 15:120-128.

40. Thon, M. R., Nuckles, E. M., and Vaillancourt, L. J. 2000. Restriction enzyme-mediated integration used to produce pathogenicity mutants of Colletotrichum graminicola. Mol. Plant-Microbe Interact. 13: 1356-1365.

41. Warren, H. L., and Nicholson, R. L. 1975. Kernel infection, seedling blight, and wilt of maize caused by Colletotrichum graminicola. Phytopathology 65:620-623.

42. Warren, L. H., Nicholson, R. L., Ullstrup, A. J., and Sharvelle, E. G. 1973. Observations of Colletotrichum graminicola on sweet corn in Indiana. Plant Dis. Rep. 57:143-144.

43. Whetten, R., and Seredoff, R. 1995. Lignin biosynthesis. Plant Cell 7:1001-1013.

44. White, D. G. (ed.) 1999. Fungal stalk rots. Pages 21-22 and 40-41 in: Compendium of Corn Diseases. 3rd ed. The American Phytopathological Society, St. Paul, MN.

45. White, D. G., and Humy, C. 1976. Methods for inoculation of corn stalks with Colletotrichum graminicola. Plant Dis. Rep. 60:898-899. 